\title{
A Prospective Multicenter Observational Study of Venous Thromboembolism after Gastric Cancer Surgery (SHISA-1601)
}

\author{
Sachiko Kaida ${ }^{a}$ Toru Miyake $^{a}$ Satoshi Murata ${ }^{a, b}$ Tsuyoshi Yamaguchi ${ }^{a}$ \\ Takeshi Tatsuta $^{c}$ Koichiro Murakamic Hiroshi Okauchid ${ }^{d}$ Shoichi Nishimurad \\ Hiroyuki Ohta $^{e}$ Hiroshi Tsuchihashif ${ }^{f}$ Masayasu Kawasaki ${ }^{f}$ \\ Katsushi Takebayashi ${ }^{a}$ Tomoharu Shimizu ${ }^{9}$ Masaji Tania \\ ${ }^{a}$ Department of Surgery, Shiga University of Medical Science, Otsu, Japan; ${ }^{b}$ Cancer Center, Shiga University of \\ Medical Science Hospital, Otsu, Japan; ' Department of Surgery, Tesseikai Neurosurgical Hospital, Osaka, Japan; \\ ${ }^{d}$ Department of Surgery, Yasu Hospital, Yasu, Japan; ' Department of Surgery, Higashi Oumi General Medical Center, \\ Higashi-Oumi, Japan; 'Department of Surgery, Bell Land General Hospital, Osaka, Japan; 9 Department of Medical \\ Safety, Shiga University of Medical Science Hospital, Otsu, Japan
}

\section{Keywords}

Gastric cancer · Gastrectomy · Venous thromboembolism (VTE) · D-dimer · Soluble fibrin

\begin{abstract}
Introduction: This study aimed to clarify the frequency and risk factors of intercurrent venous thromboembolism (VTE) in patients undergoing major curative gastric cancer surgery. Methods: This prospective, multicenter, observational study included patients with gastric cancer who underwent radical gastrectomy at 5 hospitals between June 2016 and May 2018. Patients who were preoperatively administered anticoagulants were excluded. Results: A total of 126 patients were eligible to participate. VTE occurred within 9 days postoperatively in 5 cases $(4.0 \%$; 2 symptomatic and 3 asymptomatic). Postoperative day (POD) 1 plasma D-dimer and soluble fibrin (SF) levels were significantly higher in the VTE group than in the non-VTE group. Receiver-operating characteristic curve (ROC) analysis indicated a statistically
\end{abstract}

significant ability of POD 1 D-dimer and SF levels to predict postoperative VTE development after gastrectomy; this finding was reflected by an area under the curve (AUC) of 0.97 (95\% Cl 0.92-1.0) and $0.87(95 \% \mathrm{Cl} 0.74-1.0)$, respectively. Cutoff values of D-dimer $(24.6 \mu \mathrm{g} / \mathrm{mL})$ and SF $(64.1 \mu \mathrm{g} / \mathrm{mL})$ were determined. Intraoperative blood transfusion (odds ratio [OR] 7.86), POD 1 D-dimer $\geq 24.6 \mu \mathrm{g} / \mathrm{mL}$ (OR 17.35), and POD $1 \mathrm{SF} \geq 64.1 \mu \mathrm{g} / \mathrm{mL}$ (OR 19.5) were independent predictive factors for postoperative VTE $(p<0.05)$. Conclusion: VTE occurred in $4.0 \%$ patients (1.6\% symptomatic and $2.4 \%$ asymptomatic) after gastric cancer surgery; however, with an early diagnosis and anticoagulant therapy, no patients experienced progression. Careful observation of patients with a high risk for VTE, including intraoperative blood transfusion and high POD 1 D-dimer or SF levels, would contribute to the early detection of VTE.

(C) 2021 The Author(s)

Published by S. Karger AG, Basel

This trial is registered with the UMIN Clinical Trials Registry (UMIN 000021702).
(C) 2021 The Author(s)

Published by S. Karger AG, Basel

This is an Open Access article licensed under the Creative Commons Attribution-NonCommercial-4.0 International License (CC BY-NC) (http://www.karger.com/Services/OpenAccessLicense), applicable to the online version of the article only. Usage and distribution for commercial purposes requires written permission.
Sachiko Kaida

Department of Surgery

Shiga University of Medical Science

Seta Tsukinowa-cho, Otsu, Shiga 520-2192 (Japan)

kaida@belle.shiga-med.ac.jp 


\section{Introduction}

Venous thromboembolism (VTE) includes both pulmonary thromboembolism (PE) and deep vein thrombosis (DVT). A cancer-bearing condition is an independent risk factor for VTE [1-3]. In fact, cancer patients reportedly have a 4- to 7-times higher risk of experiencing VTE than healthy people $[4,5]$. Moreover, surgery is also a major risk factor for VTE, a life-threating postoperative complication [6]. In previous reports, $24.7 \%$ of patients who underwent laparotomy due to malignant abdominal tumors developed VTE [7]. In the absence of an effective VTE prophylaxis, the rate of asymptomatic DVT is reportedly $15-40 \%$ in patients who undergo major abdominal or pelvic surgery, resulting in a $0.2-0.9 \%$ rate of fatal PE events $[4,8,9]$.

Thus, VTE is well known worldwide as a postoperative complication to avoid, for which several prevention guidelines have been proposed. The American Society of Clinical Oncology (ASCO) has issued guidelines for preventing VTE in cancer patients [10]. The VTE prevention guidelines issued by the American College of Chest Physicians (ACCP) in 2012 also advocated a VTE prevention method based on a risk score [11]. However, surgery in the abdominal region is widely defined as "a major surgery for cancer over 40 years of age," and there are few reports on the risks, due to differences among races and organs.

Gastric cancer remains the leading cause of cancerrelated death worldwide, and radical resection is the most promising treatment to ensure long-term survival [12, 13]. Many retrospective studies have examined VTE after gastrectomy. Tanizawa et al. [14] reported a 7.5\% incidence of preoperative VTE with gastric cancer in Japan. Within 2 years after surgery for gastric cancer, $2.5-7 \%$ of patients with VTE had symptoms, or the condition was incidentally identified when imaging studies were performed to evaluate a tumor or other disease status [15]. However, the incidence of VTE after gastric cancer surgery including asymptomatic VTE remains unknown.

This multicenter study aimed to prospectively examine the precise incidence of symptomatic and asymptomatic VTE in patients undergoing radical gastric cancer surgery and then evaluate the risk factors for VTE.

\section{Materials and Methods}

\section{Study Design}

The Shiga Surgical Association-1601 study was a multicenter prospective observational study of postoperative VTE in patients who underwent gastrectomy for gastric cancer at 5 hospitals in Japan. Between June 2016 and May 2018, consecutive gastric cancer patients scheduled for radical surgery were enrolled.

The inclusion criteria were as follows: (1) diagnosis of histopathologically confirmed gastric cancer, (2) scheduled for curative gastrectomy and lymph node dissection, (3) an age $\geq 20$ years at the time of consent, and (4) a performance status (PS) of $\leq 2$ on the Eastern Cooperative Oncology Group (ECOG) scale. Those with a history of thromboembolic disease before surgery or severe renal insufficiency (creatinine clearance $\leq 30 \mathrm{~mL} / \mathrm{min}$ ), who were using any anticoagulant therapy before surgery, experienced severe complications, had a PS of $\geq 3$ on the ECOG scale, or were pregnant were excluded. VTE prophylaxis after gastrectomy was chosen at the discretion of each facility.

\section{Data Collection and Variables}

Patient characteristics (age, sex, body mass index [BMI], ECOG PS, and disease progression), preoperative blood tests (hemoglobin, white blood cell [WBC] count, lymphocyte ratio, neutrophil ratio, platelet count, serum albumin, aspartate aminotransferase, alanine aminotransferase, total bilirubin, serum creatinine, C-reactive protein [CRP], prothrombin time, activated partial thromboplastin time [APTT], and D-dimer), intraoperative outcomes (procedure, operation time, blood loss, and blood transfusions) and postoperative outcomes (complications including VTE; POD 1 blood tests: WBC, platelet count, hemoglobin, D-dimer, and soluble fibrin [SF]; POD 7 blood tests: WBC, platelet count, hemoglobin, CRP, and D-dimer) were recorded on standardized forms. The patients were enrolled on the day of surgery. Registration was completed when the patient characteristics were entered on the registration form specified in the research registration address. After registering, the patient was assigned a registration number.

\section{Operative Technique}

The standard procedure at our institutions was a distal, proximal, or total gastrectomy, with regional dissection of the lymph nodes according to the 15th edition of the Japanese Gastric Cancer Classification of Gastric Carcinoma [2]. In cases of clinical stage I tumors, laparoscopic gastrectomy with D1+ lymph node dissection was performed.

\section{Outcome Measures}

The primary end point of this study was to clarify the incidence of symptomatic and asymptomatic VTE during the observation period (30 days) after radical gastric cancer surgery. The secondary end point was to analyze the risk factors for VTE after gastric cancer surgery.

Surgical complications were classified according to the Clavien-Dindo (C-D) classification system [16]. Enhanced computed tomography (CT) or ultrasonography of the lower limb was performed to diagnose VTE postoperatively when symptoms of VTE such as respiratory distress, extremity edema, or leg pain were observed, or the postoperative blood test showed levels of SF $\geq 7.6 \mu \mathrm{g} /$ $\mathrm{mL}$ or D-dimer $\geq 9.8 \mu \mathrm{g} / \mathrm{mL}$ on day 1 despite no symptoms of VTE based on past reports [17].

Since this was an exploratory study, we set the target number of cases based on feasibility, i.e., 80 patients per year were undergoing gastric cancer surgery at the participating facilities; taking into consideration the nonqualifying cases, the enrollment of 120 cases was estimated over a 2-year case accumulation period. 
Table 1. Patients' characteristics

\begin{tabular}{|c|c|c|c|}
\hline & $\begin{array}{l}\text { Non VTE } \\
\text { group }(n=121)\end{array}$ & $\begin{array}{l}\text { VTE } \\
\text { group }(n=5)\end{array}$ & $p$ value \\
\hline Age, years & $69(24-91)$ & $72(66-77)$ & 0.39 \\
\hline Sex & & & 0.59 \\
\hline Male & $92(76)$ & $3(60)$ & \\
\hline Body mass index & $22.6(16.2-32.2)$ & $23.1(19.0-24.7)$ & 0.77 \\
\hline ECOG PS $0 / 1 / 2$ & $101 / 14 / 6$ & $3 / 1 / 1$ & 0.28 \\
\hline Histological type & & & 0.14 \\
\hline Differentiated & $73(60.3)$ & $1(20)$ & \\
\hline Undifferentiated & $44(36.4)$ & $4(80)$ & \\
\hline Other & $4(3.3)$ & $0(0)$ & \\
\hline pT $_{\text {classification }}{ }^{1}$ & & & 0.27 \\
\hline $\mathrm{T} 1 \mathrm{a} / \mathrm{T} 1 \mathrm{~b}$ & $60(49.6)$ & $2(40)$ & \\
\hline $\mathrm{T} 2$ & $25(20.7)$ & $1(20)$ & \\
\hline $\mathrm{T} 3$ & $17(14.0)$ & $1(20)$ & \\
\hline $\mathrm{T} 4$ & $19(15.7)$ & $1(20)$ & \\
\hline $\mathrm{pN}_{\text {classification }}{ }^{1}$ & & & 0.86 \\
\hline N0 & $84(69.4)$ & $3(60)$ & \\
\hline N1 & $20(16.5)$ & $1(20)$ & \\
\hline N2 & $12(9.9)$ & $1(20)$ & \\
\hline N3 & $5(4.1)$ & $0(0)$ & \\
\hline pStaging $^{1}$ & & & 0.085 \\
\hline I & $78(64.5)$ & $1(20)$ & \\
\hline II & $19(15.7)$ & $2(40)$ & \\
\hline III & $20(16.5)$ & $1(20)$ & \\
\hline IV & $4(3.3)$ & $1(20)$ & \\
\hline
\end{tabular}

Values are expressed as $n(\%)$ or median (range). ${ }^{1}$ According to the 15 th Japanese Classification of Gastric Carcinoma.

\section{Statistical Analysis}

STATISTICAL analyses were performed with the Fisher exact test or Mann-Whitney U test as appropriate. Statistical calculations were performed using the Statistical Package for the Social Sciences v22.0 (IBM Institute, Armonk, NY, USA) and GraphPad Prism v8.0 (GraphPad Software, San Diego, CA, USA). For all analyses, differences were considered statistically significant at $p<$ 0.05. Using these parameters, receiver-operating characteristic (ROC) curves for D-dimer were constructed and quantified via area under the curve (AUC) analysis as well as the standard error of the mean and the corresponding 95\% CI. The Youden Index was calculated as sensitivity + specificity -1 . Logistic regression models were used for the multivariate analyses to identify risk factors associated with the development of postoperative VTE. Two-sided $p$ values $<0.05$ were considered statistically significant.

\section{Results}

\section{Patients' Characteristics}

A total of 136 patients were enrolled; 10 who were prospectively administered anticoagulants were excluded. Finally, 126 patients were enrolled in the study and fol- lowed up for 30 days postoperatively. Five patients developed VTE postoperatively; of these, 2 had symptomatic thrombosis. One patient had underlying hepatitis B and liver cirrhosis and showed no symptoms of VTE; however, the POD $1 \mathrm{D}$-dimer and SF levels were high, and enhanced CT revealed portal vein thrombosis on POD 1. In the other patient, who had a central venous port before surgery, POD $9 \mathrm{D}$-dimer and SF levels were increased, and enhanced CT revealed a small thrombus adhering to the catheter tip. Among the VTE cases, 4 patients were administered unfractionated heparin (UFH) for at least 1 week, so that the APTT was 1.5-2.5 times the facility's upper limit. Another patient with DVT of the leg was followed up but did not require any additional treatments since the symptoms resolved. No cases of VTE progression were observed during follow-up.

Table 1 shows the characteristics of the VTE and nonVTE cases. There were no significant intergroup differences in patient background factors including age, sex, BMI, ECOG PS, histological type, clinical T classification,
12
Kaida et al. 
Table 2. Intraoperative outcomes and surgical procedures

\begin{tabular}{lccc}
\hline & $\begin{array}{l}\text { Non VTE } \\
\text { group }(n=121)\end{array}$ & $\begin{array}{l}\text { VTE } \\
\text { group }(n=5)\end{array}$ & $p$ value \\
\hline Operative procedure & & & 0.07 \\
$\quad$ Distal gastrectomy & $81(66.9)$ & $2(40)$ & $2(40)$ \\
$\quad$ Total gastrectomy & $37(30.6)$ & $1(20)$ & 0.08 \\
$\quad$ Proximal gastrectomy & $3(2.5)$ & $2(40)$ & $>0.99$ \\
Reconstruction method & $41(33.9)$ & $2(40)$ & $>0.99$ \\
$\quad$ Billroth I & $77(63.6)$ & $1(20)$ & \\
$\quad$ Roux-en-Y & $3(2.5)$ & $3(60)$ & 0.15 \\
$\quad$ Esophagogastrostomy & $63(52.1)$ & $2(40)$ & 0.18 \\
Approach & $58(47.9)$ & $3(60)$ & 0.0034 \\
$\quad$ Open & $61(50.4)$ & $2(40)$ & \\
$\quad$ Laparoscopic & $60(49.6)$ & $476(252-602)$ & \\
Lymph node dissection & $339(165-652)$ & $3(60)$ & \\
$\quad$ D1/D1+ & $200(0-3695)$ & $7(5.8)$ & \\
$\quad$ D2 & & & \\
Operation time, min & & & \\
Bleeding, mL & & & \\
Intraoperative blood transfusion & & & \\
\hline
\end{tabular}

Values are expressed as $n(\%)$ or median (range).

Table 3. Preoperative and postoperative blood test outcomes

\begin{tabular}{|c|c|c|c|c|c|c|c|c|c|}
\hline & \multicolumn{3}{|l|}{ Preoperative } & \multicolumn{3}{|c|}{ Postoperative (POD 1) } & \multicolumn{3}{|c|}{ Postoperative (POD 7) } \\
\hline & $\begin{array}{l}\text { Non VTE } \\
\text { group }(n=121)\end{array}$ & $\begin{array}{l}\text { VTE } \\
\text { group }(n=5)\end{array}$ & $p$ value & $\begin{array}{l}\text { Non VTE } \\
\text { group }(n=121)\end{array}$ & $\begin{array}{l}\text { VTE } \\
\text { group }(n=5)\end{array}$ & $p$ value & $\begin{array}{l}\text { Non VTE } \\
\text { group }(n=121)\end{array}$ & $\begin{array}{l}\text { VTE } \\
\text { group }(n=5)\end{array}$ & $p$ value \\
\hline Hemoglobin, g/dL & $12.7(7.3-16.8)$ & $12.4(10.8-13.5)$ & 0.37 & $11.8(7.5-15.5)$ & $11.7(9.1-12.5)$ & 0.35 & $10.9(7.5-15.5)$ & $10.1(8.7-13.6)$ & 0.66 \\
\hline White blood cells $\left({ }^{*} 100\right)$ & $53(22-222)$ & $46(38-77)$ & 0.78 & $96.4(14.3-337)$ & $107(86-164)$ & 0.29 & $60.5(12.1-232)$ & $87(58-110)$ & 0.12 \\
\hline Lymphocytes $\left({ }^{*} 100 / \mu \mathrm{L}\right)$ & $15.2(2.73-40.4)$ & $13.3(6.84-21.4)$ & 0.49 & & & & & & \\
\hline Neutrophils $\left({ }^{*} 100 / \mu \mathrm{L}\right)$ & $30.1(9.79-184.2)$ & $31.8(26.5-57.2)$ & 0.47 & & & & & & \\
\hline Platelets $\left({ }^{*} 1,000 / \mu \mathrm{L}\right)$ & $167(13.3-501)$ & $153(22-211)$ & 0.81 & $200(11.3-523)$ & $121(15-165)$ & 0.53 & $198.5(11.3-523)$ & $188(26-261)$ & 0.81 \\
\hline Serum albumin, $\mathrm{g} / \mathrm{dL}$ & $3.9(2.2-4.8)$ & $3.6(3.0-4.1)$ & 0.33 & & & & & & \\
\hline Aspartate aminotransferase, IU/L & $20(10-90)$ & $21(16-30)$ & 0.7 & & & & & & \\
\hline Alanine transaminase, IU/L & $17(5-68)$ & $17(10-28)$ & 0.85 & & & & & & \\
\hline Total bilirubin, mg/dL & $0.6(0.2-1.86)$ & $0.4(0.78-1.25)$ & 0.52 & & & & & & \\
\hline Creatinine, mg/dL & $0.79(0.51-5.09)$ & $0.7(0.47-0.94)$ & 0.6 & & & & & & \\
\hline C-reactive protein, $\mathrm{mg} / \mathrm{dL}$ & $0.2(0.2-33.5)$ & $0.12(0.03-1.09)$ & $>0.99$ & & & & $2.84(0.2-33.5)$ & $2.39(0.75-7.48)$ & 0.66 \\
\hline Prothrombin time, \% & $12.2(10.2-120.5)$ & $11.9(11.3-100)$ & 0.67 & & & & & & \\
\hline APTT, s & $27.9(20-43.2)$ & $29.3(24.2-31.5)$ & 0.93 & & & & & & \\
\hline D-dimer, $\mu \mathrm{g} / \mathrm{mL}$ & $0.6(0.1-9.2)$ & $1.3(0.2-2.9)$ & 0.17 & $4.65(1.3-19.6)$ & $18.4(13.6-29.9)$ & $<0.0001$ & $8.0(0.2-51.0)$ & $13.1(8.6-56.9)$ & 0.0279 \\
\hline Soluble fibrin, $\mu \mathrm{g} / \mathrm{mL}$ & & & & $10.0(2.3-80.0)$ & $80.0(12.0-80.0)$ & $<0.0001$ & & & \\
\hline
\end{tabular}

Values are expressed as median (range). APTT, activated partial thromboplastin time; POD, postoperative day.

clinical $\mathrm{N}$ classification, or clinical stage according to the 15th Japanese Classification of Gastric Carcinoma. Table 2 compares the intraoperative outcomes and surgical procedures of the 2 groups. There were no significant intergroup differences in operative procedure, reconstruction method, percentage of open versus laparoscopic procedures, lymph node dissection, operation time, or blood loss. However, significantly more patients with VTE required intraoperative blood transfusions (7 cases [5.3\%] vs. 3 cases [60\%], $p=0.0034$ ).

VTE after Gastric Cancer Surgery
Pre- versus Postoperative Blood Test Results

Comparison of the blood test results revealed no significant intergroup difference in preoperative values. However, significant intergroup differences were observed in the POD 1 and POD 7 D-dimer and SF levels (Table 3).

VTE Prophylaxis and Postoperative Complications

VTE prophylaxis was performed by intermittent pneumatic compression (IPC) 126/126 [100\%]), wearing elas- 


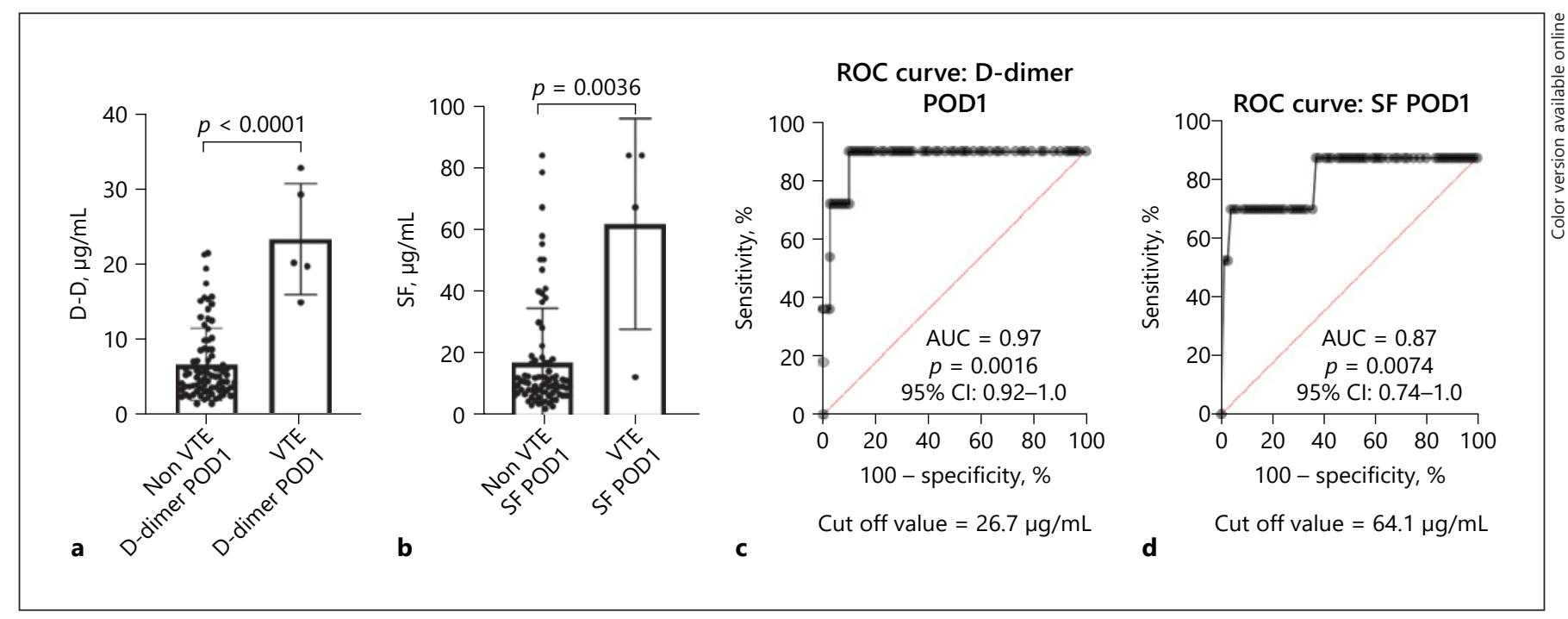

Fig. 1. Comparison of D-dimer (a) and SF (b) values on the first day after surgery. The ROC curve for the recognition of D-dimer (c) and SF (d). AUC, area under the curve; CI, confidence interval; POD, postoperative day; ROC, receiver-operating characteristic; SF, soluble fibrin.

Table 4. Univariate and multivariate analysis for VTE risk factors

\begin{tabular}{|c|c|c|c|c|c|c|}
\hline & \multicolumn{3}{|c|}{ Univariate analysis } & \multicolumn{3}{|c|}{ Multivariate analysis } \\
\hline Male sex & 2.1 & $0.27-16.17$ & 0.4061 & & & \\
\hline ECOG PS $\geq 2$ & 4.17 & $0.09-185.5$ & 0.1622 & & & \\
\hline $\mathrm{BMI} \geq 22$ & 1.17 & $0.20-6.829$ & 0.8615 & & & \\
\hline Intraoperative blood transfusion + & 18.01 & $0.67-483.5$ & $<0.0001$ & 7.86 & $1.09-56.59$ & 0.0405 \\
\hline Open surgery & 1.35 & $0.23-7.83$ & 0.7506 & & & \\
\hline Pathological stage $\geq$ III & 0.21 & $0.03-1.62$ & 0.0575 & & & \\
\hline $\mathrm{D}$-dimer $\geq 24.6 \mu \mathrm{g} / \mathrm{mL}$ on POD1 & 34.85 & $0.06-22232$ & $<0.0001$ & 17.35 & $2.49-120.8$ & 0.004 \\
\hline Soluble fibrin $\geq 64.1 \mu \mathrm{g} / \mathrm{mL}$ on POD1 & 38.45 & $0.38-3868$ & $<0.0001$ & 19.5 & $1.81-209.6$ & 0.0142 \\
\hline
\end{tabular}

tic stockings (125/126 [99\%]), or anticoagulant drugs (85/126 [67.4\%]). Enoxaparin sodium was most frequently used as a prophylaxis anticoagulant, but there was no significant intergroup difference. There was no difference between institutions in postoperative antithrombotic therapy, and IPC was used in $100 \%$ of cases during surgery and $82.5 \%$ of cases after surgery. Regarding postoperative outcomes, patients without VTE had a significantly higher occurrence of postoperative non-VTE complications than patients with VTE (C-D classification, $p=$ 0.0093).

\section{Patients with Positive D-Dimer and SF Test Results}

$D$-dimer and SF data sets were obtained for 81 patients (64.3\%). The mean POD 1 plasma D-dimer level of the VTE group was significantly higher than that of the nonVTE group (Fig. 1a). POD 1 plasma SF levels in the VTE group were also significantly higher than those in the non-VTE group (Fig. 1b). The ROC curve analysis indicated a statistically significant ability of POD $1 \mathrm{D}$-dimer and SF levels to predict postoperative VTE development after gastrectomy; these findings were reflected by an AUC value of 0.97 (95\% CI 0.92-1.0) (Fig. 1c) and 0.87 (95\% CI 0.74-1.0; Fig. 1d), respectively. The cutoff values 
of D-dimer $(24.6 \mu \mathrm{g} / \mathrm{mL})$ and SF $(64.1 \mu \mathrm{g} / \mathrm{mL})$ were determined.

\section{Uni- and Multivariate Analyses of VTE Predictive Factors}

Results from the univariate analysis of the risk factors associated with the postoperative development of VTE are shown in Table 4 . Age $\geq 70$ years $(p=0.0425)$, intraoperative blood transfusion $(p<0.0001)$, POD 1 D-dimer level $\geq 24.6 \mu \mathrm{g} / \mathrm{mL}(p<0.0001)$, and POD $1 \mathrm{SF}$ $\geq 64.1 \mu \mathrm{g} / \mathrm{mL}(p<0.0001)$ were predictive of an increased risk of VTE development. However, no other clinical parameters were predictive of postoperative VTE development.

The multivariate analysis included only the 4 variables that showed statistical significance in the univariate analyses: age $\geq 70$ years, intraoperative blood transfusion, and POD 1 D-dimer and SF levels. Among them, intraoperative blood transfusion (odds ratio [OR] 7.86; 95\% CI 1.09-56.59; $p=0.0405)$, POD 1 Ddimer level $\geq 24.6 \mu \mathrm{g} / \mathrm{mL}$ (OR 17.35; 95\% CI 2.49$120.8, p=0.00395)$, and POD 1 SF level $\geq 64.1 \mu \mathrm{g} / \mathrm{mL}$ (OR 19.5; 95\% CI 1.81-209.6, $p=0.0142$ ) were independent predictive factors for postoperative VTE development.

\section{Discussion}

The frequency of VTE after gastric cancer surgery has been reported in a randomized controlled trial in Korea [18]. The overall VTE frequency was $2.1 \%$. All patients underwent duplex ultrasonography (DUS) routinely on postoperative day 4, after which they were followed up for clinical symptoms to identify VTE. In Japan, it has been reported that 7.2\% of DVT was found by lower limb echo on 7 days after surgery for gastric cancer in a single-center study [19]. However, the incidence of VTE after gastric cancer surgery, including asymptomatic VTE diagnosed by more objective and sensitive images of CT scans, remains unknown. Therefore, it is worthwhile to report the frequency of symptomatic VTE confirmed by ultrasonography or a CT scan and asymptomatic VTE confirmed by a contrast CT scan taken based on elevated of D-dimer and/or SF levels after gastric cancer surgery in a multicenter prospective study. In this study, we found VTE in $4.0 \%$ patients ( $1.6 \%$ symptomatic and $2.4 \%$ asymptomatic) after gastric cancer surgery.

There are many research reports on perioperative VTE prophylaxis in gastrointestinal surgery, and the ASCO guidelines suggest that VTE prophylaxis be ad- ministered at least 7-10 days after cancer surgery [10]. Especially in patients with a high risk of VTE, a maximum of 4 weeks of continuous VTE prophylaxis should be considered. The ACCP guidelines for the prevention of VTE recommend low-molecular-weight heparin (LMWH) for patients undergoing abdominal surgery for cancer [20]. Widely used LMWH is characterized as having a high anti-Xa/thrombin activity ratio compared to UFH and relatively less able to inhibit thrombin; it therefore has less influence on platelets and fewer hemorrhage-related side effects [21-23]. In a large randomized controlled trial in South Korea, postoperative VTE occurred significantly higher frequently in the IPC-only group compared to the IPC + LMWH group (3.6 vs. $0.6 \% ; p=0.008$ ), and the incidence of postoperative bleeding complications was significantly higher in the IPC + LMWH group than in the IPC-only group (9.1 vs. $1.2 \% ; p<0.001)$ after gastric cancer surgery [18]. From Japan, Osaki et al. [19] performed lower limb echo before and 7 days after surgery for gastric cancer, and reported a DVT of 4.4 and $7.2 \%$, respectively.

We conducted this study to determine the incidence of patients who develop VTE after radical surgery for gastric cancer through a multicenter study in Japan. In this study, all surgeons at the 5 institutes used enoxaparin sodium postoperatively and no adverse bleeding events occurred. This study clarified that the incidence of VTE after radical gastric cancer surgery was $4.0 \%$. Of the 5 VTE cases $(4.0 \%), 3(60 \%)$ were identified within 2 days after surgery; in all 3 , enoxaparin sodium was used only once. This study found that LMWH administered from POD 2 could not completely prevent postoperative VTE.

Li et al. [24] reviewed 8,611 reports and identified the positive risk factors for VTE of age, radiation, need for blood transfusion, and operative time. Nielsen et al. [25] also reported that blood transfusion was a major risk factor for VTE in bariatric surgery. These reports demonstrated the need to monitor thrombosis markers and patient symptoms in cases in which blood transfusion was performed during surgery, and to evaluate imaging studies immediately to diagnose VTE and start treatment. Our study also showed that in elderly patients ( $\geq 70$ years old), intraoperative blood transfusion could be a risk factor for VTE development after gastrectomy.

$\mathrm{D}$-dimer is generally thought to increase in patients who are old, have a history of cancer, and undergo surgery [5]. In this study, D-dimer on days 1 and 7 after surgery for gastric cancer was also increased in patients who did not develop VTE, compared to preoperatively (Table 3 ). However, patients with high D-dimer on the first day after 
surgery still had a significantly higher incidence of VTE. This is a new finding that goes beyond the conventional knowledge of high D-dimer level after cancer surgery. Together with the SF levels, high D-dimer levels on the first day after surgery could be used as a high predictor of VTE development after surgery.

For predicting VTE, no previous reports suggested a detailed cutoff value for postoperative VTE in gastric cancer patients. Kimura et al. [26] reported that after gastrointestinal cancer surgery, D-dimer on the 7 th day after the operation was significantly higher than that on the 3rd day after the operation. However, there has been no report showing the cut-off value of $\mathrm{D}$-dimer that predicts VTE on the first day after surgery. Therefore, we focused on the blood test results from POD 1 for early VTE detection. The POD $1 \mathrm{D}$-dimer and SF levels were significantly higher in the VTE group, and the cutoff values obtained by drawing the ROC curve were $24.6 \mu \mathrm{g} / \mathrm{mL}$ for $\mathrm{D}$-dimer and $64.1 \mu \mathrm{g} / \mathrm{mL}$ for SF. Imaging tests based on the elevated POD 1 D-dimer and SF levels could enable the early detection of VTE, which may lead to early anticoagulant therapy. Even in this study, an abnormal POD 1 D-dimer or SF levels led to the early diagnosis of asymptomatic VTE; as a result, rapid anticoagulation treatment was provided, resulting in a good prognosis without VTE deterioration.

One of the limitations of this study was that prophylaxis anticoagulants to prevent postoperative VTE were used only in $67.4 \%$ of patients. It is unclear whether the low incidence of VTE was related to postoperative prophylaxis anticoagulant use starting on POD 2. In addition, 5 cases of VTE were insufficiently powered to analyze the risk factors for VTE. It is expected that cases will be further accumulated under the unified use of postoperative prophylaxis anticoagulants and that the risk factors for VTE development will be analyzed in detail.

Another limitation was that POD 1 and POD 7 D-dimer and SF levels were obtained in $64.3 \%$ of cases. This was because the measurements could not be taken at some general hospitals due to medical insurance problems. However, our study findings suggest the significance of a high D-dimer or SF value in the early postoperative period and demonstrate the real incidence of VTE after radical gastric cancer surgery; therefore, we will be able to conduct this validation study to confirm the significance of early postoperative D-dimer and SF levels as risk factors for the development of postoperative DVT in gastric cancer surgery.

\section{Conclusion}

VTE occurred in $4.0 \%$ of patients ( $1.6 \%$ symptomatic and $2.4 \%$ asymptomatic) after gastric cancer surgery, without VTE deterioration due to the early diagnosis of VTE and early anticoagulant therapy. The careful observation of patients with high-risk factors and predictive factors for VTE, including intraoperative blood transfusion and high POD $1 \mathrm{D}$-dimer or SF level, would contribute to the early detection of VTE.

\section{Acknowledgement}

We would like to thank Editage (www.editage.com) for English language editing.

\section{Statement of Ethics}

All procedures performed in studies involving human participants were in accordance with the ethics standards of the institutional and/or national research committee and the 1964 Helsinki Declaration and its later amendments or comparable standards. Informed consent was obtained from all individual participants included in the study. This study was approved by the Research Ethics Committee of Shiga University of Medical Science (No. R2015-228).

\section{Conflict of Interest Statement}

The authors declare that they have no conflicts of interest.

\section{Funding Sources}

The authors received no specific funding for this work.

\section{Author Contributions}

S.K.: conceptualization, methodology, and writing of the original draft; T.M.: validation and formal analysis; S.M.: writing (review and editing); T.Y., T.T., and S.N.: investigation and resources; K.M., H.O., H.O., H.T., M.K., and K.T.: data curation and resources; T.S.: software, supervision, and project administration; M.T.: supervision, writing (review and editing), and funding acquisition.

\footnotetext{
References 1 Prandoni P, Falanga A, Piccioli A. Cancer and venous thromboembolism. Lancet Oncol. 2005 Jun;6(6):401-10.

2 Furie B, Furie BC. Mechanisms of thrombus formation. N Engl J Med. 2008 Aug;359(9): 938-49.

3 Varki A. Trousseau's syndrome: multiple definitions and multiple mechanisms. Blood. 2007 Sep;110(6):1723-9.
}

Kaida et al. 
4 Geerts WH, Bergqvist D, Pineo GF, et al. Prevention of venous thromboembolism: American College of Chest Physicians EvidenceBased Clinical Practice Guidelines (8th Edition). Chest. 2008 Jun;133(6 Suppl):381S-453S.

5 Heit JA, Silverstein MD, Mohr DN, Petterson TM, O'Fallon WM, Melton LJ 3rd. Risk factors for deep vein thrombosis and pulmonary embolism: a population-based case-control study. Arch Intern Med. 2000 Mar;160(6): 809-15.

6 Silverstein MD, Heit JA, Mohr DN, Petterson TM, O'Fallon WM, Melton LJ 3rd. Trends in the incidence of deep vein thrombosis and pulmonary embolism: a 25 -year populationbased study. Arch Intern Med. 1998 Mar; 158(6):585-93.

7 Sakon M, Kakkar AK, Ikeda M, Sekimoto M, Nakamori S, Yano M, et al. Current status of pulmonary embolism in general surgery in Japan. Surg Today. 2004;34(10):805-10.

8 Mismetti P, Laporte S, Darmon JY, Buchmüller A, Decousus H. Meta-analysis of low molecular weight heparin in the prevention of venous thromboembolism in general surgery. Br J Surg. 2001 Jul;88(7):913-30.

9 Geahchan N, Basile M, Tohmeh M; DIONYS registry. Venous thromboembolism prophylaxis in patients undergoing abdominal and pelvic cancer surgery: adherence and compliance to ACCP guidelines in DIONYS registry. Springerplus. 2016 Sep;5(1):1541.

10 Lyman GH, Bohlke K, Khorana AA, Kuderer NM, Lee AY, Arcelus JI, et al.; American Society of Clinical Oncology. Venous thromboembolism prophylaxis and treatment in patients with cancer: american society of clinical oncology clinical practice guideline update 2014. J Clin Oncol. 2015 Feb;33(6):654-6.

11 Gould MK, Garcia DA, Wren SM, et al. Prevention of VTE in nonorthopedic surgical patients: Antithrombotic Therapy and Prevention of Thrombosis, 9th ed: American College of Chest Physicians Evidence-Based Clinical Practice Guidelines. Chest. 2012 Feb;141(2 Suppl):e227S-e277S.
12 Bang YJ, Van Cutsem E, Feyereislova A, Chung HC, Shen L, Sawaki A, et al.; ToGA Trial Investigators. Trastuzumab in combination with chemotherapy versus chemotherapy alone for treatment of HER2-positive advanced gastric or gastro-oesophageal junction cancer (ToGA): a phase 3, open-label, randomised controlled trial. Lancet. 2010 Aug. 376(9742):687-97.

13 Chang SC, Liu KH, Hung CY, Tsai CY, Hsu JT, Yeh TS, et al. Adjuvant Chemotherapy Improves Survival in Stage III Gastric Cancer after D2 Surgery. J Cancer. 2018 Jan;9(1):8191.

14 Tanizawa Y, Bando E, Kawamura T, Tokunaga M, Makuuchi R, Iida K, et al. Prevalence of deep venous thrombosis detected by ultrasonography before surgery in patients with gastric cancer: a retrospective study of 1140 consecutive patients. Gastric Cancer. 2017 Sep; 20(5):878-86.

15 Lee KW, Bang SM, Kim S, Lee HJ, Shin DY, Koh Y, et al. The incidence, risk factors and prognostic implications of venous thromboembolism in patients with gastric cancer. J Thromb Haemost. 2010 Mar;8(3):540-7.

16 Clavien PA, Barkun J, de Oliveira ML, Vauthey JN, Dindo D, Schulick RD, et al. The Clavien-Dindo classification of surgical complications: five-year experience. Ann Surg. 2009 Aug;250(2):187-96.

17 Niimi R, Hasegawa M, Sudo A, Shi D, Yamada T, Uchida A. Evaluation of soluble fibrin and $\mathrm{D}$-dimer in the diagnosis of postoperative deep vein thrombosis. Biomarkers. 2010 Mar; 15(2):149-57.

18 Jung YJ, Seo HS, Park CH, Jeon HM, Kim JI, Yim HW, et al. Venous Thromboembolism Incidence and Prophylaxis Use After Gastrectomy Among Korean Patients With Gastric Adenocarcinoma: The PROTECTOR Randomized Clinical Trial. JAMA Surg. 2018 Oct; 153(10):939-46.
19 Osaki T, Saito H, Fukumoto Y, Kono Y, Murakami $Y$, Shishido $Y$, et al. Risk and incidence of perioperative deep vein thrombosis in patients undergoing gastric cancer surgery. Surg Today. 2018 May;48(5):525-33.

20 Holbrook A, Schulman S, Witt DM, et al. Evidence-based management of anticoagulant therapy: Antithrombotic Therapy and Prevention of Thrombosis, 9th ed: American College of Chest Physicians Evidence-Based Clinical Practice Guidelines. Chest. 2012 Feb; 141(2 Suppl):e152S-84S.

21 Felder S, Rasmussen MS, King R, et al. Prolonged thromboprophylaxis with low molecular weight heparin for abdominal or pelvic surgery. Cochrane Database Syst Rev. 2009 Jan 21;(1):CD004318.

22 Riess H, Habbel P, Jühling A, Sinn M, Pelzer U. Primary prevention and treatment of venous thromboembolic events in patients with gastrointestinal cancers - Review. World J Gastrointest Oncol. 2016 Mar;8(3):258-70.

23 Guyatt GH, Akl EA, Crowther M, et al. Executive summary: Antithrombotic Therapy and Prevention of Thrombosis, 9th ed: American College of Chest Physicians EvidenceBased Clinical Practice Guidelines. Chest. 2012 Feb;141(2 Suppl):7S-47S.

$24 \mathrm{Li} \mathrm{M}$, Guo Q, Hu W. Incidence, risk factors, and outcomes of venous thromboembolism after oncologic surgery: A systematic review and meta-analysis. Thromb Res. 2019 Jan; 173:48-56.

25 Nielsen AW, Helm MC, Kindel T, Higgins R, Lak K, Helmen ZM, et al. Perioperative bleeding and blood transfusion are major risk factors for venous thromboembolism following bariatric surgery. Surg Endosc. 2018 May; 32(5):2488-95.

26 Kimura Y, Oki E, Ando K, Saeki H, Kusumoto T, Maehara Y. Incidence of Venous Thromboembolism Following Laparoscopic Surgery for Gastrointestinal Cancer: A Single-Center, Prospective Cohort Study. World J Surg. 2016 Feb;40(2):309-14. 